\title{
Real-life assessment of the multidimensional nature of dyspnoea in COPD outpatients
}

\author{
Capucine Morélot-Panzini ${ }^{1,2}$, Hélène Gilet ${ }^{3}$, Bernard Aguilaniu ${ }^{4}$, \\ Philippe Devillier ${ }^{5}$, Alain Didier ${ }^{6}$, Thierry Perez ${ }^{7}$, Christophe Pignier $^{8}$, \\ Benoit Arnould ${ }^{3}$ and Thomas Similowski ${ }^{1,2}$
}

\begin{abstract}
Affiliations: 'Sorbonne Universités, UPMC Université Paris 06, INSERM, UMRS1158 “Neurophysiologie respiratoire expérimentale et clinique", Paris, France. ${ }^{2}$ AP-HP, Groupe Hospitalier Pitié-Salpêtrière Charles Foix, Service de Pneumologie et Réanimation Médicale (Département "R3S"), Paris, France. ${ }^{3}$ Patient-Centered Outcomes, Mapi, Lyon, France. ${ }^{4}$ Université Joseph Fourier, Grenoble, France. ${ }^{5}$ UPRES EA220, Hôpital Foch, Suresnes, France. 'Service de Pneumologie, Hôpital Larrey, Centre Hospitalier Régional et Universitaire de Toulouse, Toulouse, France. ${ }^{7}$ Clinique des Maladies Respiratoires, Centre Hospitalier Régional et Universitaire de Lille, Lille, France. ${ }^{8}$ Pierre Fabre Médicament, Castres, France.
\end{abstract}

Correspondence: Capucine Morélot-Panzini, Service de Pneumologie et Réanimation Médicale (Département "R3S"), Groupe Hospitalier Pitié-Salpêtrière Charles Foix, 47-83 Bd de l'Hôpital, 75651 Paris, Cedex 13, France. E-mail: capucine.morelotapsl.aphp.fr

ABSTRACT Dyspnoea is a prominent symptom of chronic obstructive pulmonary disease (COPD). Recent multidimensional dyspnoea questionnaires like the Multidimensional Dyspnea Profile (MDP) individualise the sensory and affective dimensions of dyspnoea. We tested the MDP in COPD outpatients based on the hypothesis that the importance of the affective dimension of dyspnoea would vary according to clinical characteristics.

A multicentre, prospective, observational, real-life study was conducted in 276 patients. MDP data were compared across various categories of patients (modified Medical Research Council (mMRC) dyspnoea score, COPD Assessment Test (CAT) score, Global Initiative for Chronic Obstructive Lung Disease (GOLD) airflow obstruction categories, GOLD “ABCD” categories, and Hospital Anxiety and Depression Scale (HADS)). Univariate and multivariate regressions were conducted to explore factors influencing the affective dimension of dyspnoea. Cluster analysis was conducted to create homogeneous patient profiles.

The MDP identified a more marked affective dimension of dyspnoea with more severe mMRC, CAT, 12-item Short-Form Health Survey mental component, airflow obstruction and HADS. Multivariate analysis identified airflow obstruction, depressive symptoms and physical activity as determinants of the affective dimension of dyspnoea. Patients clustered into an "elderly, ex-smoker, severe disease, no rehabilitation" group exhibited the most marked affective dimension of dyspnoea.

An affective/emotional dimension of dyspnoea can be identified in routine clinical practice. It can contribute to the phenotypic description of patients. Studies are needed to determine whether targeted therapeutic interventions can be designed and whether they are useful.

@ERSpublications

The affective dimension of dyspnoea can be assessed in COPD outpatients and could help personalise treatment http://ow.ly/YHRiW

This article has supplementary material available from erj.ersjournals.com

Received: Nov 292015 | Accepted after revision: Feb 202016 | First published online: April 132016

Support statement: Pierre Fabre Médicament funded the study logistics and data analysis as performed by Mapi, and paid honoraria to C. Morélot-Panzini, P. Devillier, A. Didier, T. Perez and T. Similowski. Funding information for this article has been deposited with FundRef.

Conflict of interest: Disclosures can be found alongside the online version of this article at erj.ersjournals.com

Copyright OERS 2016 


\section{Introduction}

Dyspnoea is a prominent clinical feature of chronic obstructive pulmonary disease (COPD) and the presence of dyspnoea has an intrinsic prognostic value [1]. The relationship between dyspnoea and exercise tolerance and activities of daily living makes it a dominant driver of COPD-related quality of life impairment $[2,3]$. In recent years, dyspnoea has been recognised to be multidimensional, like pain [4]. This is readily apparent in the 2012 American Thoracic Society definition, in which dyspnoea is "a subjective experience of breathing discomfort that consists of qualitatively distinct sensations that vary in intensity [and] vary in their unpleasantness and in their emotional and behavioral significance" [5] (see also [6]).

Nevertheless, in clinical practice, dyspnoea is generally evaluated by means of one-dimensional tools (e.g. visual analogue scale or Borg scale) or its impact on exercise capacity ("operational" tools such as the modified Medical Research Council (mMRC) scale or the baseline and transition dyspnoea indices). This approach does not take stock of the complexity of dyspnoea, and may tend to neglect its emotional dimension, as the healthcare provider's understanding of what dyspnoea actually means for the patients is most probably very far from reality [7].

Multidimensional tools have been proposed to address this issue, including the Dyspnoea-12 score [8], to a certain extent the Cancer Dyspnoea Scale [9] and, more specifically, the Multidimensional Dyspnea Profile (MDP) [10-13] (see extensive review in [14]). The MDP is derived from a conceptual model largely accepted to study pain. Designed to evaluate both experimental dyspnoea and clinical dyspnoea, the MDP assesses immediate respiratory discomfort, the qualities of the corresponding respiratory sensation, and the concurrent emotions (see online supplementary material, supplement S1). It is of note that the MDP refers to a specified time-frame that can vary in length depending on study design. Published evidence suggests that the MDP is appropriate for use in clinical settings (e.g. in patients admitted to an emergency department [11]) and in experimental settings [10, 15], where it is able to distinguish immediate perception and emotional response; that it is reproducible [13]; and that it is responsive to treatment and to clinical improvement $[11,15]$.

COPD is probably the most common cause of chronic dyspnoea in adults. COPD-related dyspnoea cannot be fully corrected even by optimal care associating smoking cessation, bronchodilators and pulmonary rehabilitation. It therefore has a sort of "refractory" or "residual" nature in most patients. Emotional disturbances are frequent in the COPD population, with a high prevalence of anxiety and depression [16], to which dyspnoea and its consequences probably contribute $[17,18]$. For these reasons, we set out to describe the affective dimension of dyspnoea and its determinants in COPD patients. Based on pilot clinical experiences $[11,12]$, we hypothesised that applying the MDP to COPD patients enrolled on a real-life basis would be feasible and would allow the relative characterisation of the sensory and affective dimensions, or components, of dyspnoea. We further hypothesised that the importance of the affective dimension of dyspnoea in COPD patients would vary according to phenotypic characteristics of the disease. We conducted a prospective, observational, real-life multicentre study to test these hypotheses.

\section{Material and methods}

\section{Study design and population}

The study was conducted in compliance with the Declaration of Helsinki and was approved by the appropriate French legal and ethical authority (Comité de Protection des Personnes Ile de France 6, Pitié-Salpêtrière, Paris, France). Informed consent was obtained from all participants.

74 respiratory physicians recruited patients from their outpatient clinics between April 2012 and February 2013 (private practice $n=28(37.8 \%)$, hospital practice $n=23(31.1 \%)$, mixed practice $n=22(29.1 \%)$, missing data $n=1)$. Patients were eligible when they were aged $\geqslant 40$ years, were smokers or ex-smokers with cumulative smoking of $>10$ pack-years, had a diagnosis of COPD and a forced expiratory volume in $1 \mathrm{~s}$ (FEV1) to forced vital capacity ratio $<0.70$ and $\mathrm{FEV}_{1}<80 \%$ predicted, and had not suffered from an acute exacerbation during the previous 6 weeks. Recruiting physicians were asked to include patients in whom they intended to introduce any form of therapeutic modification for whatever reason (excluding exacerbation). Exclusion criteria were limited to another concomitant chronic respiratory disease, the presence of any form of severely disabling conditions compromising the patient's participation in the study, the presence of alcohol or drug addiction, and insufficient command of the French language. Each recruiting physician was asked to initially include three patients, namely one patient from each of the Global Initiative for Chronic Obstructive Lung Disease (GOLD) airflow obstruction categories II, III and IV; additional patients could then be recruited, with the same distribution pattern (competitive recruitment until completion of inclusions).

The protocol included three assessments: inclusion visit, first follow-up visit (3 months after the inclusion visit) and second follow-up (2 weeks after the first follow-up visit, by mail) (figure 1). 


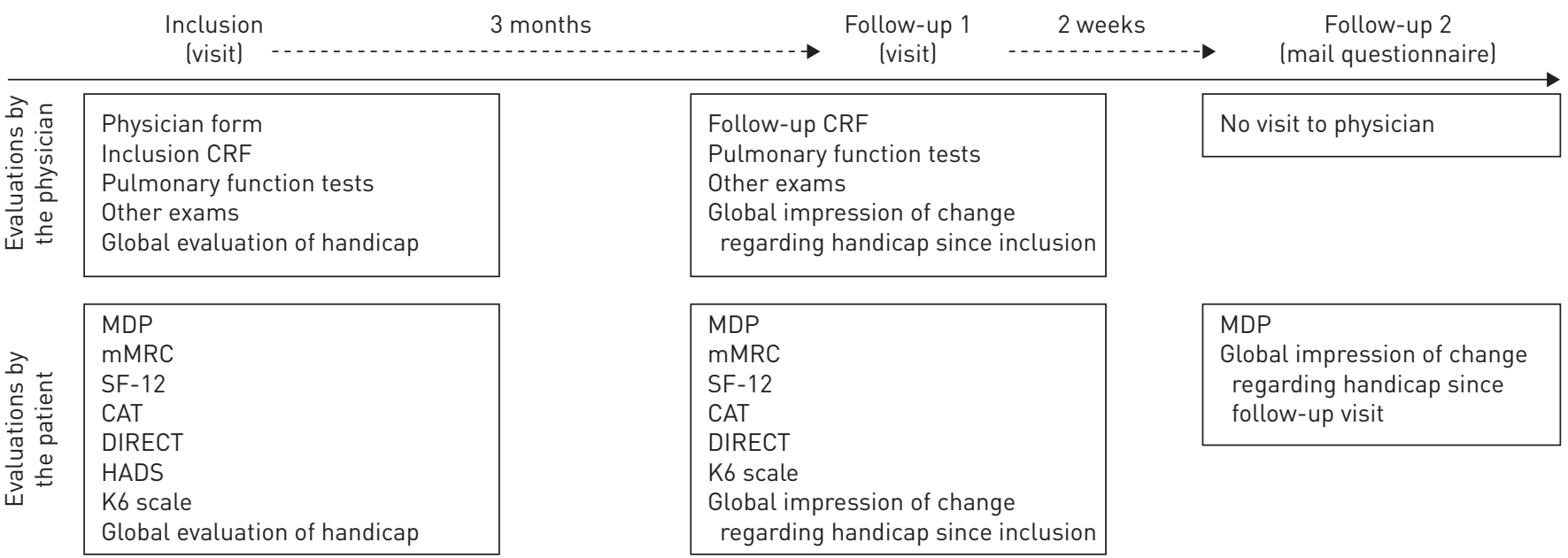

FIGURE 1 Study design. CRF: case report form; MDP: Multidimensional Dyspnea Profile; mMRC: modified Medical Research Council dyspnoea scale; SF-12: 12-item Short-Form Health Survey; CAT: COPD Assessment Test; DIRECT: Disability Related to COPD Tool; HADS: Hospital Anxiety and Depression Scale; K6 scale: Kessler's 6-question scale for assessment of nonspecific psychological distress.

\section{Data collection}

Standard clinical and historical data and pulmonary function tests were collected (table 1). In addition, the patients were presented with several patient-reported outcome (PRO) questionnaires, including: the mMRC dyspnoea scale; the 12-item Short-Form Health Survey (SF-12), analysed in terms of its mental and physical composite scales (MCS and PCS, respectively) with higher scores corresponding to better health status; Kessler's 6-question scale for assessment of nonspecific psychological distress, with higher scores corresponding to less severe psychological distress [19]; the COPD Assessment Test (CAT) with four categories (<10 low impact, 10-20 moderate impact, 20-30 high impact, $>30$ very high impact); the

\section{TABLE 1 Patient characteristics at the time of inclusion}

\begin{tabular}{lc} 
Age years & $66.4 \pm 9.9(\mathrm{n}=273)$ \\
Male & 71.7 \\
Occupational status & 13.4 \\
Employed & 4.0 \\
Unemployed & 71.7 \\
Retired & 9.4 \\
Long-term sick leave & 33.0 \\
Active smoker & $29.0 \pm 19.4(\mathrm{n}=87)$ \\
Cumulative smoking pack-years & \\
GOLD stage for severity of airflow obstruction & 33.7 \\
II & 36.2 \\
III & 30.1 \\
IV & \\
GOLD “ABCD" category & 8.3 \\
A & 19.9 \\
B & 8.0 \\
C & 59.8 \\
D & 52.2 \\
Exacerbations in the past 12 months & $1.8 \pm 1.1$ \\
श1 exacerbation & $44.8 \pm 16.1(\mathrm{n}=264)$ \\
Exacerbations & $149.4 \pm 43.9(\mathrm{n}=145)$ \\
FEV1 \% predicted & $0.3 \pm 0.1(\mathrm{n}=183)$ \\
FRC \% predicted & \\
IC/TLC ratio & 55.8 \\
Concomitant diseases & 31.2 \\
Cardiovascular disease & \\
Neuropsychiatric disease & \\
\hline
\end{tabular}

Data are presented as mean \pm SD or $\%$, unless otherwise stated. GOLD: Global Initiative for Chronic Obstructive Lung Disease; FEV1: forced expiratory volume in $1 \mathrm{~s}$; FRC: functional residual capacity; IC/TLC: inspiratory capacity/total lung capacity. ${ }^{\#}$ : from medical history and/or patient's files. 
Disability Related to COPD Tool (DIRECT) with higher scores corresponding to more severe disability [20]; and the Hospital Anxiety and Depression Scale (HADS) with four levels $(<7$ normal, 8-10 mild, 11-14 moderate, 15-21 severe).

In addition to the HADS, recruiting physicians were also asked whether they thought that the patients presented clinical symptoms of depression.

Finally, recruiting physicians and patients were both asked to perform a subjective evaluation of the patient's global handicap on a four-point scale (“mild", "moderate", "severe" or "very severe").

\section{Multidimensional Dyspnea Profile}

The MDP consists of 11 items evaluating both the sensory and affective dimensions of dyspnoea. One item (A1) assesses the unpleasantness of dyspnoea on a 0-10 visual numerical scale anchored by "neutral" (0) and "unbearable" (10). Five items assess the sensory dimension of dyspnoea, both in terms of quality and intensity (on a scale of $0-10$ ). Five items assess the affective dimension of dyspnoea, also in terms of quality and intensity (on a scale of 0-10). Two domain scores were calculated: an "immediate perception domain" score (S) as the sum of A1 intensity and the intensities of the five sensory descriptors; and an "emotional response domain" score (A2) as the sum of the five emotional descriptors [11, 14]. In this study, patients were asked to focus on the worst breathing experience that they had had during the past 2 weeks, and to specifically describe this experience (supplement S2). The MDP can generally be completed in $\leqslant 3$ min.

The psychometric performance of the MDP was also specifically assessed in the study population, with satisfactory results in terms of construct validity and reliability (supplement S3).

The French version of the MDP used in this study has been developed and linguistically validated according to a standard process of forward and backward translations followed by clinicians' validation and patients' cognitive debriefing. This was performed by a professional company specialising in this field (Mapi, Lyon, France) (supplement S4).

\section{Statistical analyses}

All analyses were conducted on patients who met all inclusion criteria and who completed at least one item of the MDP questionnaire at inclusion.

The MDP-S and -A2 scores were compared across mMRC categories, CAT categories, HADS anxiety levels, HADS depression levels, GOLD airflow obstruction categories, and GOLD “ABCD” categories using ANOVA.

Simple and partial Pearson correlations were computed to explore the relationships between the MDP "immediate perception domain" score (S) and its "emotional response domain" score (A2), lung function, and PRO data (CAT, DIRECT and SF-12 scores), first without adjustment and then after adjusting for FEV1 (\% predicted) and for both the mMRC dyspnoea score and FEV1 (\% predicted). The strengths of the correlations of $\mathrm{S}$ and A2 with the CAT, DIRECT and SF-12 scores were compared using the Hotelling-Williams procedure [21].

To more clearly understand the factors that can influence the level of the affective dimension of dyspnoea (A2) as reported by the patients, univariate regressions were performed against all variables collected during the study (demographics, clinical characteristics, physiological data, treatments and comorbidities) (supplement S5). All variables related to A2 with a p-value $<0.20(n=26)$ were then entered into a stepwise multivariate analysis.

For exploratory purposes and to test whether or not the affective dimension of dyspnoea could help to categorise patients, a cluster analysis was conducted to create homogeneous patient profiles using a two-step approach: multiple correspondence analysis (MCA) was first applied to the raw data, and then a hybrid clustering was applied to the output of the MCA. 21 variables related to demographics, COPD characteristics, other symptoms and PRO scores were used in the cluster analysis (age, sex, type of usual physical activity, smoking habits, body mass index, time since diagnosis, at least one cardiovascular disease, cough, exacerbations in the past 12 months, depressive symptoms, anxious symptoms, FEV1, inspiratory capacity to total lung capacity ratio, ADO index (age, dyspnoea, obstruction) [22], treatment including inhaled corticosteroids alone or associated with long-acting bronchodilators, home oxygen therapy, pulmonary rehabilitation, mMRC, SF-12 PCS, SF-12 MCS, DIRECT score). Resulting profiles were then characterised in terms of demographic and clinical characteristics, and the MDP "immediate perception domain" score (S) and its "emotional response domain" score (A2) were then described and compared between the identified patient profiles using ANOVA.

Analyses were performed with SAS software for Windows (Version 9.2; SAS Institute, Inc., Cary, NC, USA) and SPAD software (Version 7.0; Coheris Spad, Courbevoie, France). Data are summarised in terms of their median and interquartile range (IQR; quartile 1 to quartile 3). The limit for statistical significance was set at 5\%. 


\section{Results}

\section{Study population}

300 patients were recruited and 276 of them met all inclusion criteria and completed at least one item of the MDP: they constitute the main analysis population (table 1). 229 of these patients also completed the MDP at the first follow-up, and 87 patients also completed the MDP at the second follow-up and reported that they had been stable between the first and second follow-ups (see supplement S3, psychometric evaluation). The PRO questionnaire scores are summarised in table 2.

\section{TABLE 2 Patient-related outcomes at inclusion}

\begin{tabular}{|c|c|}
\hline \multicolumn{2}{|l|}{ mMRC grade } \\
\hline 0 & 7.6 \\
\hline 1 & 27.5 \\
\hline 2 & 20.7 \\
\hline 3 & 14.5 \\
\hline 4 & 9.4 \\
\hline Missing & 20.3 \\
\hline \multicolumn{2}{|l|}{ SF-12\# } \\
\hline PCS score & $34.4 \pm 10.0(n=252)$ \\
\hline MCS score & $46.5 \pm 11.3(n=252)$ \\
\hline \multicolumn{2}{|l|}{ CAT total score } \\
\hline Low impact & 14.5 \\
\hline Medium impact & 41.3 \\
\hline High impact & 31.2 \\
\hline Very high impact & 8.0 \\
\hline Missing & 5.1 \\
\hline DIRECT total score $e^{\pi}$ & $14.5 \pm 8.3(n=274)$ \\
\hline \multicolumn{2}{|l|}{ HADS } \\
\hline \multicolumn{2}{|l|}{ Anxiety score } \\
\hline Normal & 56.5 \\
\hline Mild & 12.7 \\
\hline Moderate & 11.6 \\
\hline Severe & 5.4 \\
\hline Missing & 13.8 \\
\hline \multicolumn{2}{|l|}{ Depression score } \\
\hline Normal & 49.3 \\
\hline Mild & 15.6 \\
\hline Moderate & 13.8 \\
\hline Severe & 6.9 \\
\hline Missing & 14.5 \\
\hline K6 total score ${ }^{+}$ & $22.4 \pm 5.1(n=270)$ \\
\hline \multicolumn{2}{|l|}{ Global assessment of handicap ${ }^{\S}$} \\
\hline Mild & 8.3 \\
\hline Moderate & 32.6 \\
\hline Severe & 41.3 \\
\hline Very severe & 15.6 \\
\hline Missing & 2.2 \\
\hline \multicolumn{2}{|c|}{ Global impression of change since inclusion regarding global handicap ${ }^{\S}$} \\
\hline Very much/much improved & 10.1 \\
\hline Minimally improved & 33.7 \\
\hline No change & 26.1 \\
\hline Minimally worsened & 5.4 \\
\hline Very much/much worsened & 3.3 \\
\hline Missing & 21.4 \\
\hline
\end{tabular}

Data are presented as \% or mean \pm SD, unless otherwise stated. mMRC: modified Medical Research Council dyspnoea scale; SF-12: 12-item Short-Form Health Survey; PCS: physical composite scale; MCS: mental composite scale; CAT: COPD Assessment Test; DIRECT: Disability Related to COPD Tool; HADS: Hospital Anxiety and Depression Scale; K6: Kessler's 6-question scale for assessment of nonspecific psychological distress. ": higher score=better health status; ": range 0-34, higher score=higher level of disability; ${ }^{+}$: range 6-30, higher score=less severe psychological distress; ${ }^{\S}$ : self-evaluated. 


\section{Multidimensional Dyspnea Profile}

97 of the $276 \mathrm{MDP}$ questionnaires were fully completed. The median (IQR) number of missing items for the other cases was $1(0-3)$.

The median (IQR) rating for immediate unpleasantness of dyspnoea (A1) was 6.0 (3.5-7.0). The sensory quality most often chosen as "best applying" was "air hunger" (27\%), followed by "breathing a lot" (19\%). The median (IQR) ratings were as follows: "air hunger" 5.0 (2.0-8.0), "breathing a lot" 4.5 (1.0-7.0), "breathing work/effort" 3.0 (1.0-6.0), "chest tightness" $3.0(0.0-6.0)$ and "mental effort" $2.0(0.0-6.0)$. The emotional responses were rated as follows: anxiety 3.0 (0.0-6.0), frustration $2.0(0.0-5.0)$, anger $1.0(0.0-5.0)$, fear $1.0(0.0-5.0)$ and depression $0.0(0.0-4.0)$. The "immediate perception domain" score (S) was rated 25.0 (13.0-37.0), whereas the "emotional response domain" score (A2) was rated 10.0 (3.0-20.0) (figure 2).

In general, patients reporting higher MDP-S and -A2 scores were those with the highest mMRC scores, the worst global assessment, DIRECT, CAT and HADS scores, and higher GOLD stages (see supplementary material). Marked differences were observed between the MDP-S/other variables relationships and the MDP-A2/other variables relationships. Similarly, figure 3 shows that, compared with S, A2 exhibited a disproportionate increase between $\mathrm{mMRC}$ grade 3 and $\mathrm{mMRC}$ grade 4 . Figure 4 shows the distribution of $S$ and A2 according to GOLD stages II-IV and "ABCD" classification. Table 3 summarises the correlations between MDP-S and -A2 scores and the CAT, DIRECT, and SF-12 PCS and MCS scores, with and without adjustment for FEV1 and mMRC. Notably, the correlations of outcomes of the physical dimension were
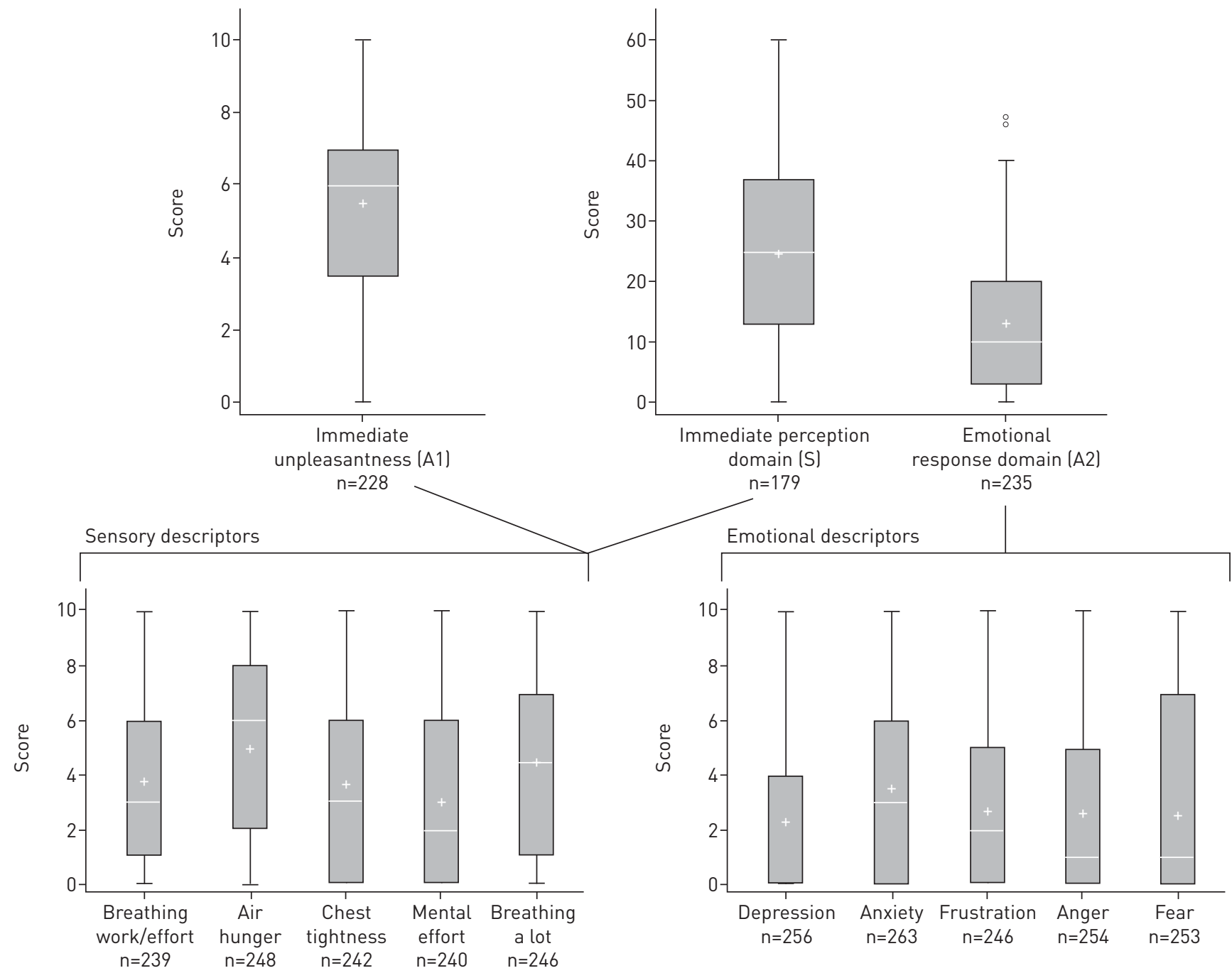

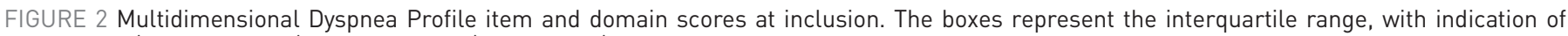
the median (horizontal line) and the mean (white cross). The whiskers correspond to the minimum and maximum values recorded. Outliers are

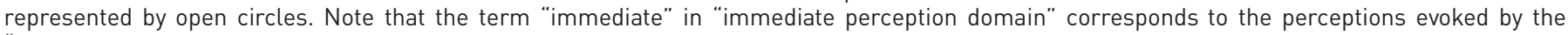
"worst dyspnoeic event" focused on by the patients, irrespective of the moment at which this event occurred within the 15 days' recall period. 


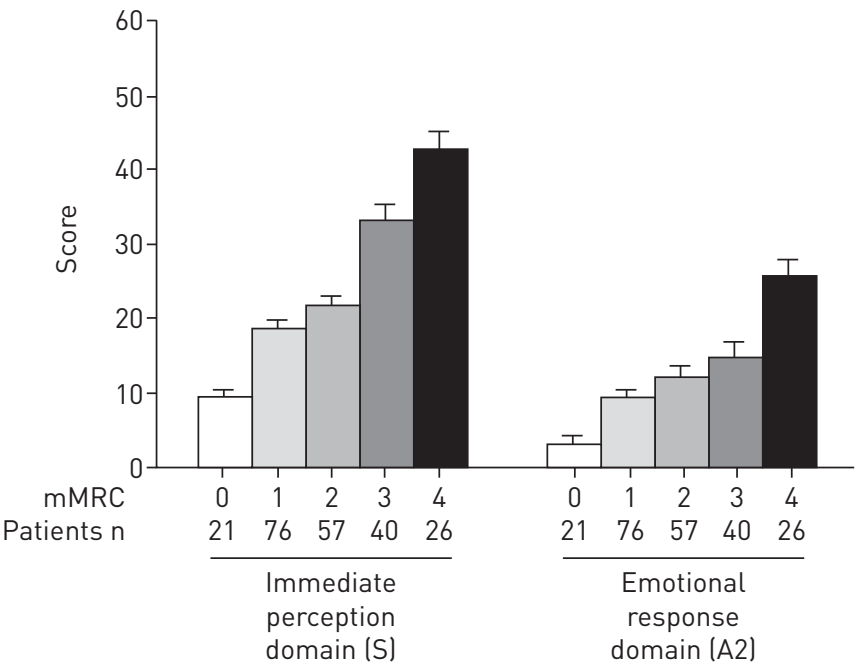

FIGURE 3 Multidimensional Dyspnea Profile domain scores in the study population, stratified according to the modified Medical Research Council (mMRC) dyspnoea severity grades. Data are presented as mean \pm SEM. Note that the term "immediate" in "immediate perception domain" corresponds to the perceptions evoked by the "worst dyspnoeic event" focused on by the patients, irrespective of the moment at which this event occurred within the 15 days' recall period.

significantly stronger with $\mathrm{S}$ than with A2 (CAT and DIRECT were significantly more closely associated with $S$ than with A2). The correlation of outcome of the mental dimension was stronger with A2 than with S (SF-12 MCS was significantly more closely associated with A2 than with S).

\section{Factors influencing the affective dimension of dyspnoea}

Multivariate analysis identified a three-variable model (type of physical activity, presence of clinical symptoms of depression, FEV1) that was significantly associated with A2 (table 4). Results of univariate analyses for parameters tested in the multivariate model, i.e. with $\mathrm{p}<0.20$, are provided in supplement S5.

Table 5 describes the five homogeneous classes of patients isolated by the cluster analysis. In summary, class 1 corresponds to very active patients with mild and recent COPD, marked hyperinflation and minimal disability. Class 2 corresponds to moderately active, overweight patients with mild and recent COPD and a slight impact on disability. Class 3 corresponds to older patients, ex-smokers, suffering from severe and longstanding COPD, with a major impact on daily activities (confined to housework activities), who had not received pulmonary rehabilitation. Class 4 corresponds to current smokers, with very low levels of activity, a major clinical impact of coughing and anxiety, with cardiovascular comorbidities. Class 5 corresponds to
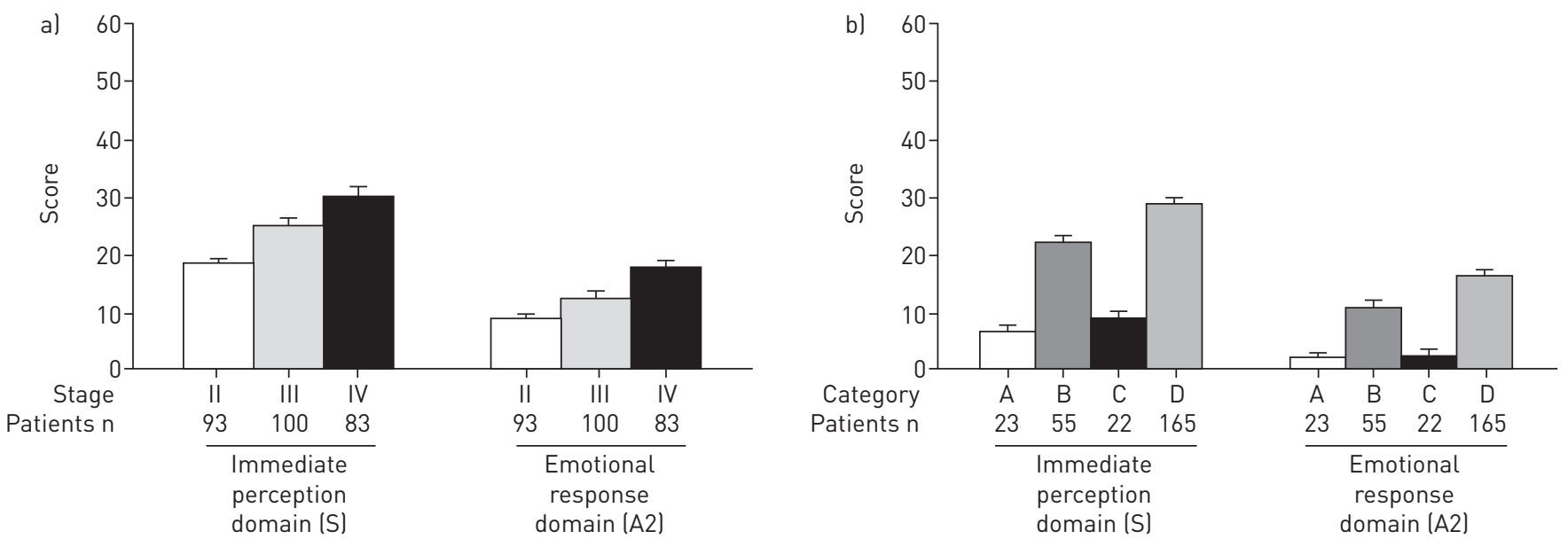

FIGURE 4 Multidimensional Dyspnea Profile domain scores, stratified by a) severity of airflow obstruction according to Global Initiative for Chronic Obstructive Lung Disease (GOLD), and b) the GOLD "ABCD" integrative classification. Data are presented as mean \pm SEM. Note that the term "immediate" in "immediate perception domain" corresponds to the perceptions evoked by the "worst dyspnoeic event" focused on by the patients, irrespective of the moment at which this event occurred within the 15 days' recall period. 
TABLE 3 Correlations between Multidimensional Dyspnea Profile immediate ${ }^{\#}$ perception domain (S) and emotional response domain (A2) scores and measures of handicap and quality of life

\begin{tabular}{|c|c|c|c|c|}
\hline & Patients n & Immediate $^{\#}$ perception domain (S) $\rho$ & Emotional response domain (A2) $\rho$ & p-value ${ }^{\pi}$ \\
\hline \multicolumn{5}{|l|}{ No adjustment } \\
\hline CAT score & 159 & 0.77 & 0.63 & 0.001 \\
\hline SF-12 PCS score & 154 & -0.50 & -0.41 & 0.149 \\
\hline SF-12 MCS score & 154 & -0.43 & -0.60 & 0.005 \\
\hline \multicolumn{5}{|c|}{ Adjustment for FEV 1 and $m M R C$} \\
\hline SF-12 PCS score & 130 & -0.16 & -0.13 & 0.747 \\
\hline SF-12 MCS score & 130 & -0.25 & -0.51 & 0.001 \\
\hline \multicolumn{5}{|c|}{$\begin{array}{l}\text { CAT: COPD Assessment Test; DIRECT: Disability Related to COPD Tool; SF-12: } 12 \text {-item Short-Form Health Survey; PCS: physical composite } \\
\text { scale; MCS: mental composite scale; FEV1: forced expiratory volume in } 1 \mathrm{~s} \text {; mMRC: modified Medical Research Council dyspnoea scale. ": the } \\
\text { term "immediate" corresponds to the perceptions evoked by the "worst dyspnoeic event" focused on by the patients, irrespective of the moment } \\
\text { at which this event occurred within the } 15 \text { days' recall period; "П: Hotelling-Williams test comparing correlation coefficients, in bold when p<0.05. }\end{array}$} \\
\hline
\end{tabular}

older patients, ex-smokers, with severe and longstanding COPD, but who have received pulmonary rehabilitation and who are still very active. Figure 5 depicts the $S$ and A2 scores according to these five classes, with a statistically significant difference demonstrated between the five classes on both $\mathrm{S}$ and A2 scores.

\section{Discussion}

This study shows that the multidimensional nature of dyspnoea can be captured in the routine clinical setting, as the MDP is able to identify and distinguish sensory and affective dimensions (immediate perception domain and emotional reaction domain, respectively) of the dyspnoea reported by unselected COPD patients. The study also brings novel information about dyspnoea in COPD outpatients, by showing that its sensory and affective components do not vary in the same manner with the various characteristics of the disease, and by showing that the affective dimension of dyspnoea can contribute to patient phenotyping.

\section{Strengths and weaknesses}

Patients were recruited by a population of respiratory physicians representative of all types of medical practice. These physicians received the necessary training to explain the MDP (using a standard script) and the other questionnaires to their patients, but the extent of this training was purposely kept compatible with daily clinical practice. The number of patient exclusion criteria was kept to a minimum.

We believe that the main strength of the study resides in its pragmatic, real-life nature. In addition, de novo psychometric validation of the MDP (see supplement S3) was conducted in order to verify that its previously described properties held true in our study population $[11,13,14]$.

\begin{tabular}{|c|c|c|c|c|}
\hline & Parameter estimate & $F$ value & p-value & $\mathbf{R}^{2}$ \\
\hline Intercept & 19.4 & & & $0.27^{\pi}$ \\
\hline Type of usual physical activity & & 2.7 & 0.047 & \\
\hline Physical training ${ }^{\#}$ & 0.0 & & & \\
\hline Maintenance of physical activity & -3.1 & & & \\
\hline Recreational & 0.9 & & & \\
\hline Housework only & 2.7 & & & \\
\hline Depressive symptoms & & 31.5 & $<0.001$ & \\
\hline No $\#$ & 0.0 & & & \\
\hline Yes & 10.0 & & & \\
\hline FEV $1 \%$ predicted & -0.2 & 25.0 & $<0.001$ & \\
\hline
\end{tabular}

There were 227 patients with no missing data on the three parameters included in the model. FEV1: forced expiratory volume in $1 \mathrm{~s} .{ }^{\#}$ : reference; ${ }^{\text {? }}$ : overall value. 
TABLE 5 Patient phenotypic profiles according to cluster analysis

\begin{tabular}{|c|c|c|c|c|c|}
\hline & \multicolumn{5}{|c|}{ Class } \\
\hline & 1 & 2 & 3 & 4 & 5 \\
\hline Patients n & 62 & 67 & 35 & 48 & 64 \\
\hline Mean age years & $66.1(n=61)$ & $62.0(n=67)$ & $70.1(n=34)$ & $65.3(n=48)$ & $70.1(n=63)$ \\
\hline Male & 83.9 & 77.6 & 62.9 & 66.7 & 62.5 \\
\hline \multicolumn{6}{|l|}{ Type of usual physical activity } \\
\hline Housework only & 33.9 & 56.7 & 82.9 & 81.3 & 65.6 \\
\hline Recreational & 22.6 & 35.8 & 8.6 & 2.1 & 1.6 \\
\hline Maintenance & 29.0 & 3.0 & 2.9 & 6.3 & 12.5 \\
\hline Physical training & 11.3 & 4.5 & 2.9 & 8.3 & 18.8 \\
\hline Active smoker & 29.0 & 53.7 & 11.4 & 50.0 & 14.1 \\
\hline \multicolumn{6}{|l|}{$\mathrm{BMI} \mathbf{k g} \cdot \mathrm{m}^{-2}$} \\
\hline$\leqslant 20$ & 3.2 & 16.4 & 17.1 & 14.6 & 23.4 \\
\hline $20-25$ & 46.8 & 20.9 & 34.3 & 39.6 & 37.5 \\
\hline $25-30$ & 30.6 & 23.9 & 22.9 & 31.3 & 29.7 \\
\hline$>30$ & 17.7 & 38.8 & 25.7 & 14.6 & 9.4 \\
\hline Mean time since diagnosis years & $4.8(n=61)$ & $5.4(n=66)$ & $12.6(n=32)$ & $7.5(n=48)$ & $10.9(n=63)$ \\
\hline$\geqslant 1$ exacerbation in the past 12 months & 29.0 & 50.7 & 74.3 & 64.6 & 54.7 \\
\hline Mean FEV $1 \%$ predicted & $57.8(n=62)$ & $52.0(n=66)$ & $31.2(n=34)$ & $41.3(n=48)$ & $35.3(n=64)$ \\
\hline \multicolumn{6}{|l|}{ IC/TLC ratio } \\
\hline$\leqslant 0.2$ & 8.1 & 14.9 & 28.6 & 10.4 & 34.4 \\
\hline $0.2-0.3$ & 9.7 & 17.9 & 11.4 & 45.8 & 31.3 \\
\hline$>0.3$ & 43.5 & 35.8 & 14.3 & 20.8 & 9.4 \\
\hline Missing & 38.7 & 31.3 & 45.7 & 22.9 & 25.0 \\
\hline Rehabilitation & 8.1 & 9.0 & 2.9 & 12.5 & 25.0 \\
\hline Oxygen & 8.1 & 6.0 & 71.4 & 20.8 & 53.1 \\
\hline Anxious symptoms & 11.3 & 7.5 & 57.1 & 91.7 & 15.6 \\
\hline Depressive symptoms & 4.8 & 7.5 & 31.4 & 62.5 & 0.0 \\
\hline \multicolumn{6}{|l|}{ mMRC grade } \\
\hline 0 & 30.6 & 1.5 & 0.0 & 2.1 & 0.0 \\
\hline 1 & 41.9 & 44.8 & 0.0 & 27.1 & 10.9 \\
\hline 2 & 12.9 & 26.9 & 0.0 & 27.1 & 28.1 \\
\hline 3 & 3.2 & 4.5 & 17.1 & 16.7 & 32.8 \\
\hline 4 & 0.0 & 3.0 & 65.7 & 2.1 & 0.0 \\
\hline Missing & 11.3 & 19.4 & 17.1 & 25.0 & 28.1 \\
\hline \multicolumn{6}{|l|}{ SF-12 } \\
\hline Mean PCS & $44.1(n=57)$ & $38.1(n=61)$ & $25.3(n=34)$ & $33.7(n=44)$ & $26.6(n=56)$ \\
\hline Mean MCS & $54.4(n=57)$ & $48.7(n=61)$ & $36.7(n=34)$ & $38.1(n=44)$ & $48.5(n=56)$ \\
\hline
\end{tabular}

Data are presented as \% unless otherwise stated. BMI: body mass index; FEV1: forced expiratory volume in $1 \mathrm{~s}$; IC/TLC: inspiratory capacity/total lung capacity; mMRC: modified Medical Research Council dyspnoea scale; SF-12: 12-item Short-Form Health Survey; PCS: physical composite scale; MCS: mental composite scale.

We acknowledge that the study also has several weaknesses. First, a significant amount of missing data was observed for certain descriptive criteria and certain outcomes. For example, only 97 of the 276 MDP questionnaires were fully completed, which might seem problematic; however, the median amount of missing answers was only one out of 12 questions, and it should be kept in mind that in this study the patients had a large number of questionnaires to complete. Secondly, the large number of participating physicians is bound to have induced a certain degree of heterogeneity, but this can also be considered to be a strength. Thirdly, the consecutive nature of inclusions was not strictly controlled. Finally, we could not evaluate the responsiveness of the MDP, because only a small number of patients chose the exact same type of dyspnoea-triggering event to focus on for the "before" and "after" measures.

On this point, it is important to remember that the MDP "is intended to refer to a specific event or time" [14], as opposed to, for example, the Dyspnoea-12 scale, which refers to an indeterminate recent period [8]. We asked our patients to focus on "their worst experience within the last 15 days". This slightly deviates from the MDP doctrine because it introduces some recall subjectivity regarding "the event", but this was a constraint of our "real-life" preoccupation (it would have been somewhat artificial to designate a unique dyspnoea-triggering activity for all the patients, clinically too vague to "lump" the last 2 weeks together, and too restrictive to focus on the day before the visit). Insofar as previous data have shown that the test-retest reliability of the MDP can 


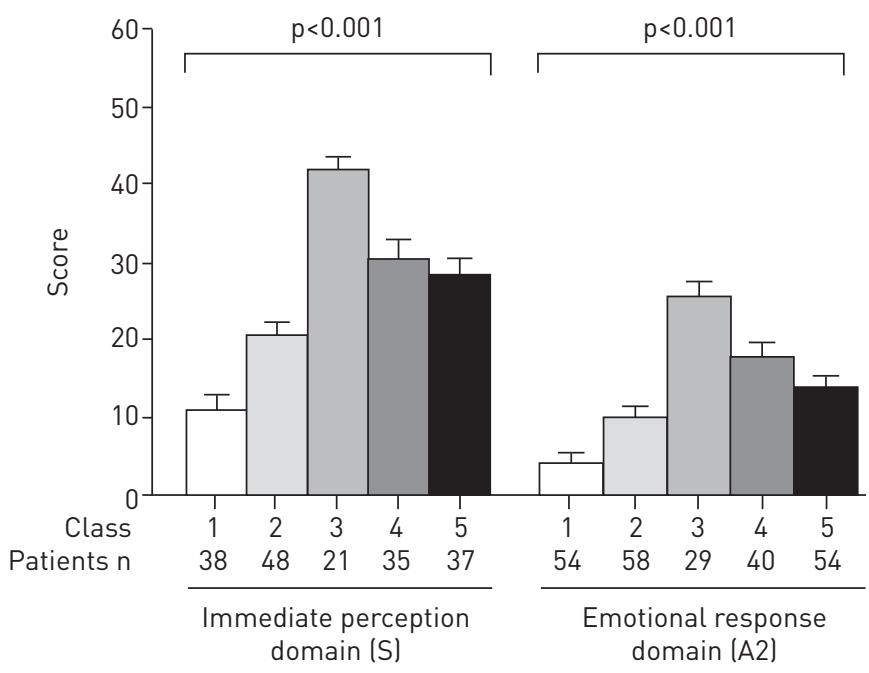

FIGURE 5 Multidimensional Dyspnea Profile (MDP) domain scores according to the five phenotypic clusters identified. Data are presented as mean \pm SEM. $p$-value from ANOVA comparing MDP scores between all five clusters. Note that the term "immediate" in "immediate perception domain" corresponds to the perceptions evoked by the "worst dyspnoeic event" focused on by the patients, irrespective of the moment at which this event occurred within the 15 days' recall period.

be weak for recall periods of 4-6 weeks [13], we took the precaution to limit our recall period to 2 weeks. Reassuringly from a methodological standpoint, the test-retest reliability of the MDP applied with these choices was good in our population (supplement S3, table S5), and we found test-retest intraclass correlation coefficients similar to those obtained by PARSHALL et al. [13] over a very short recall period (during the emergency department visit) and way above those reported by the same authors over a 4-6-week interval.

\section{Contribution to the available MDP dataset}

The MDP is a recent tool for the evaluation of dyspnoea. It has been developed over several years, and, as only to be expected, has been somewhat unstable during this development [14]. The consolidated version of the questionnaire was only made easily and freely available in 2015 [14]. Consequently, only a limited volume of "MDP dyspnoea" data is currently available.

The team that developed the questionnaire has published an extensive review [14]. Very briefly, the use of an MDP precursor in a study of experimental dyspnoea demonstrated that, for a given level of sensory intensity, the unpleasantness of respiratory sensations varied with their nature ("air hunger" sensation was more unpleasant than "work/effort" sensation) [10]. A study conducted in 151 adult patients admitted to three urban emergency departments in the southwestern USA and presenting with respiratory symptoms of various origins showed that the MDP exhibited good reliability, validity and responsiveness to clinical improvement [11]. This study is important because it establishes the validity and the reliability of the instrument for the first time according to a generic approach (unselected population) and under pragmatic conditions.

Our study differs from the 2012 study by MeEK et al. [11] in that we studied stable patients suffering from a single disease (COPD), while MeEK et al. [11] studied acutely ill patients suffering from various respiratory diseases. Nevertheless, our results on validity and reliability are similar to those reported by MeEK et al. [11]. Parshall et al. [13] completed the analysis performed by MeEK et al. [11] by evaluating test-retest reliability in the same cohort of patients. As aforementioned, we observed similar performances in this regard in our patients. It is of note that, in the studies by PARSHALl et al. [13] and MeEK et al. [11], sensory and affective scores were higher than those obtained in our study, possibly due to the acute nature of the dyspnoeic episode evaluated. A small pilot study in COPD patients demonstrated that activities of daily living elicit similar sensory and affective responses, as evaluated by the MDP, to experimental dyspnogenic stimuli [12].

Our study therefore extends the available MDP dataset, in the wider perspective of the description of the affective dimension of dyspnoea in COPD [23-26]. One important point is that our data lend support to the validity of the MDP as an actual multidimensional instrument. This is clearly shown by the psychometric validation (see supplementary material), but is also apparent in the clinical validation. In this respect, the "immediate perception domain" (S) component and the "emotional response domain" (A2) component of the MDP exhibited a different pattern of correlation with the various PROs (table 3). Reassuringly, S was more strongly correlated with "physical" PROs than with A2 (e.g. SF-12 PCS or DIRECT score) and A2 was more strongly correlated with "mental" PROs than with S (e.g. SF-12 MCS). 
Our results also show that the affective component of the MDP increases with the severity of dyspnoea as assessed one-dimensionally (figure 2), but that there is a disproportionate difference in A2 between the mMRC grade 3 and $\mathrm{mMRC}$ grade 4 categories (figure 3 ), which was not observed for $\mathrm{S}$. The multivariate analysis performed on our dataset (table 4) identified three factors as being significantly linked to the affective dimension of dyspnoea. Among these factors, the existence of clinical depression does not come as a surprise and is somewhat reminiscent of the interferences that have been described between dyspnoea and affective state in COPD patients [27]. The relationship between A2 and the type of physical activity reported by the patients is an interesting finding, inasmuch as exercise training and more generally pulmonary rehabilitation have been shown to improve dyspnoea-related anxiety [25] and more generally the affective dimension of dyspnoea [28]. In fact, in a study conducted in 48 COPD patients undergoing a rehabilitation programme, WADELL et al. [28] observed that the affective dimension of dyspnoea was more responsive to the programme than its sensory dimension. It has also been shown that COPD patients exhibiting the highest baseline dyspnoea-related fear derive greater benefits from rehabilitation than other patients [29].

At first sight, the strongly significant relationship between A2 and FEV1 appears to be less expected and could be considered to be surprising, especially as FEV1 has the reputation of being poorly correlated with dyspnoea, but this reputation may not be entirely warranted [30]. However, in a study conducted among 98 COPD patients in whom affective descriptors of dyspnoea were correlated with indicators of physical disability, Williams et al. [31] reported that "affective descriptors or the emotional response to the sensation of breathlessness have a significant relationship with severity of COPD impairments", as assessed by the BODE index (body mass index, airflow obstruction, dyspnoea, exercise capacity). WiLliams et al. [31] interpreted this observation as indicating that affective descriptors of dyspnoea reflect the degree of threat imposed by the sensation. Our data suggest that "frustration" plays an important role in the affective dimension of dyspnoea (figure 2). Frustration is likely to become greater with the progressive shrinking of daily activities associated with progression of obstruction, which could also contribute to explaining our observations and those of WiLLiams et al. [31].

\section{Perspectives}

Cluster analysis in COPD is a complex issue, and our intention in the present study was only to test whether or not the affective dimension of dyspnoea could contribute to COPD phenotyping. Figure 5 and table 5 suggest that this could be the case. Being able to identify an affective dimension of dyspnoea, or, more importantly, identify a population of COPD patients who are highly likely to exhibit a strong affective dimension, might have important therapeutic implications. COPD-related dyspnoea, in the wider sense of the term, is often only partially responsive to the usual symptomatic approaches. Likewise, a great many COPD patients experience "residual" exertional dyspnoea despite "maximal" pharmacological and nonpharmacological (rehabilitation) treatment, not to mention refractory dyspnoea that persists at rest despite treatment. It would therefore be desirable to widen the therapeutic arsenal against dyspnoea. Targeting the affective dimension of dyspnoea is most likely a promising option in this perspective.

Certain interventions have already demonstrated specific effects in this domain. This is the case for distractive auditory stimuli, which have been shown to reduce the unpleasantness of dyspnoea more than its intensity, during a 6-min walking test in COPD patients [32]. Perhaps more interesting from a practical point of view, cognitive behavioural strategies may have a particular impact on dyspnoea-related anxiety [33]. Recent data have shown that self-management programmes may prove particularly efficient in this regard [34]. This type of intervention is not easy to implement and requires particular skills and professional competences. It is therefore important to select patients most likely to benefit from these interventions based on a "personalised" medicine approach. The results of our clustering analysis suggest that this could be a realistic objective (figure 5 and table 5). It is of note that "simple" pulmonary rehabilitation resources are also scarce, and, according to the results of this study, selecting patients who have an important affective dimension to their dyspnoea and limited physical activity could be a means to optimise these resources.

In conclusion, our study provides the first large-scale demonstration that the MDP can be used in a clinical setting, and it demonstrates that it is possible to identify patients with a prominent affective dimension of dyspnoea. Further studies are needed to evaluate the clinical usefulness of this instrument to assess the efficacy of therapeutic interventions, and its value to tailor novel therapies to individual patient profiles.

\section{Acknowledgements}

The authors are indebted to Véronique Delagnes-Charasson (Toulouse, France) for her involvement in the initial phases of the study and would like to thank Anthony Saul, professional medical editor (Paris, France), for his help with English style and grammar. Parts of the data constituting the present manuscript have been presented in abstract form during the 2014 "Congrès de Pneumologie de Langue Française", Lille, France; during the 2014 European Respiratory Society congress, Munich, Germany; and during the 2015 International Society for Pharmacoeconomics and Outcome Research congress, Milan, Italy. 
Pierre Fabre Médicament did not intervene in data analysis, and did not interfere with writing strategy. C. Pignier, an employee of Pierre Fabre Médicament, is listed among the authors for his contribution to the study design and to the final manuscript.

\section{References}

1 Nishimura K, Izumi T, Tsukino M, et al. Dyspnea is a better predictor of 5-year survival than airway obstruction in patients with COPD. Chest 2002; 121: 1434-1440.

2 Hajiro T, Nishimura $\mathrm{K}$, Tsukino $\mathrm{M}$, et al. A comparison of the level of dyspnea vs disease severity in indicating the health-related quality of life of patients with COPD. Chest 1999; 116: 1632-1637.

3 Tsiligianni I, Kocks J, Tzanakis N, et al. Factors that influence disease-specific quality of life or health status in patients with COPD: a review and meta-analysis of Pearson correlations. Prim Care Respir J 2011; 20: 257-268.

4 Lansing RW, Gracely RH, Banzett RB. The multiple dimensions of dyspnea: review and hypotheses. Respir Physiol Neurobiol 2009; 167: 53-60.

5 Parshall MB, Schwartzstein RM, Adams L, et al. An official American Thoracic Society statement: update on the mechanisms, assessment, and management of dyspnea. Am J Respir Crit Care Med 2012; 185: 435-452.

6 Laviolette L, Laveneziana P. Dyspnoea: a multidimensional and multidisciplinary approach. Eur Respir J 2014; 43: $1750-1762$

7 Currow DC, Johnson MJ. Distilling the essence of breathlessness: the first vital symptom. Eur Respir J 2015; 45: $1526-1528$

8 Yorke J, Russell AM, Swigris J, et al. Assessment of dyspnea in asthma: validation of the Dyspnea-12. J Asthma 2011; 48: 602-608.

9 Tanaka K, Akechi T, Okuyama T, et al. Development and validation of the Cancer Dyspnoea Scale: a multidimensional, brief, self-rating scale. Br J Cancer 2000; 82: 800-805.

10 Banzett RB, Pedersen SH, Schwartzstein RM, et al. The affective dimension of laboratory dyspnea: air hunger is more unpleasant than work/effort. Am I Respir Crit Care Med 2008; 177: 1384-1390.

11 Meek PM, Banzett R, Parshall MB, et al. Reliability and validity of the multidimensional dyspnea profile. Chest 2012; 141: 1546-1553.

12 O’Donnell CR, Schwartzstein RM, Lansing RW, et al. Dyspnea affective response: comparing COPD patients with healthy volunteers and laboratory model with activities of daily living. BMC Pulm Med 2013; 13: 27.

13 Parshall MB, Meek PM, Sklar D, et al. Test-retest reliability of multidimensional dyspnea profile recall ratings in the emergency department: a prospective, longitudinal study. BMC Emerg Med 2012; $12: 6$.

14 Banzett RB, O'Donnell CR, Guilfoyle TE, et al. Multidimensional Dyspnea Profile: an instrument for clinical and laboratory research. Eur Respir J 2015; 45: 1681-1691.

15 Banzett RB, Adams L, O'Donnell CR, et al. Using laboratory models to test treatment: morphine reduces dyspnea and hypercapnic ventilatory response. Am J Respir Crit Care Med 2011; 184: 920-927.

16 Maurer J, Rebbapragada V, Borson S, et al. Anxiety and depression in COPD: current understanding, unanswered questions, and research needs. Chest 2008; 134: Suppl. 4, 43S-56S.

17 Bailey PH. The dyspnea-anxiety-dyspnea cycle - COPD patients' stories of breathlessness: "It's scary /when you can't breathe". Qual Health Res 2004; 14: 760-778.

18 Chavannes NH, Huibers MJ, Schermer TR, et al. Associations of depressive symptoms with gender, body mass index and dyspnea in primary care COPD patients. Fam Pract 2005; 22: 604-607.

19 Kessler RC, Andrews G, Colpe LJ, et al. Short screening scales to monitor population prevalences and trends in non-specific psychological distress. Psychol Med 2002; 32: 959-976.

20 Aguilaniu B, Gonzalez-Bermejo J, Regnault A, et al. Disability related to COPD tool (DIRECT): towards an assessment of COPD-related disability in routine practice. Int J Chron Obstruct Pulmon Dis 2011; 6: 387-398.

21 Williams EJ. The comparison of regression variables. J R Stat Soc Series B Stat Methodol 1959; 21: 396-399.

22 Puhan MA, Garcia-Aymerich J, Frey M, et al. Expansion of the prognostic assessment of patients with chronic obstructive pulmonary disease: the updated BODE index and the ADO index. Lancet 2009; 374: 704-711.

23 Carrieri-Kohlman V, Donesky-Cuenco D, Park SK, et al. Additional evidence for the affective dimension of dyspnea in patients with COPD. Res Nurs Health 2010; 33: 4-19.

24 Carrieri-Kohlman V, Gormley JM, Douglas MK, et al. Differentiation between dyspnea and its affective components. West J Nurs Res 1996; 18: 626-642.

25 Carrieri-Kohlman V, Gormley JM, Eiser S, et al. Dyspnea and the affective response during exercise training in obstructive pulmonary disease. Nurs Res 2001; 50: 136-146.

26 Smith J, Albert P, Bertella E, et al. Qualitative aspects of breathlessness in health and disease. Thorax 2009; 64: 713-718.

27 von Leupoldt $\mathrm{A}$, Taube $\mathrm{K}$, Henkhus $\mathrm{M}$, et al. The impact of affective states on the perception of dyspnea in patients with chronic obstructive pulmonary disease. Biol Psychol 2010; 84: 129-134.

28 Wadell K, Webb KA, Preston ME, et al. Impact of pulmonary rehabilitation on the major dimensions of dyspnea in COPD. COPD 2013; 10: 425-435.

29 Janssens T, De Peuter S, Stans L, et al. Dyspnea perception in COPD: association between anxiety, dyspnea-related fear, and dyspnea in a pulmonary rehabilitation program. Chest 2011; 140: 618-625.

30 Perez T, Burgel PR, Paillasseur JL, et al. Modified Medical Research Council scale vs Baseline Dyspnea Index to evaluate dyspnea in chronic obstructive pulmonary disease. Int J Chron Obstruct Pulmon Dis 2015; 10: 1663-1672.

31 Williams M, Cafarella P, Olds T, et al. Affective descriptors of the sensation of breathlessness are more highly associated with severity of impairment than physical descriptors in people with COPD. Chest 2010; 138: 315-322.

32 von Leupoldt A, Taube K, Schubert-Heukeshoven S, et al. Distractive auditory stimuli reduce the unpleasantness of dyspnea during exercise in patients with COPD. Chest 2007; 132: 1506-1512.

33 Norweg A, Collins EG. Evidence for cognitive-behavioral strategies improving dyspnea and related distress in COPD. Int J Chron Obstruct Pulmon Dis 2013; 8: 439-451.

34 Donesky D, Nguyen HQ, Paul SM, et al. The affective dimension of dyspnea improves in a dyspnea self-management program with exercise training. J Pain Symptom Manage 2014; 47: 757-771. 